Zeszyty Naukowe Szkoły Głównej Gospodarstwa Wiejskiego w Warszawie

Problemy Rolnictwa Światowego tom 18 (XXXIII), zeszyt 1, 2018: 176-182

DOI: $10.22630 /$ PRS.2018.18.1.16

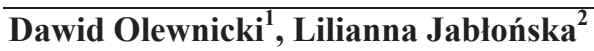

Szkoła Główna Gospodarstwa Wiejskiego w Warszawie

\title{
Polski handel zagraniczny produktami kwiaciarskimi
}

\section{Polish Foreign Trade in Floricultural Product}

\begin{abstract}
Synopsis. Celem badań był polski eksport i import roślin ozdobnych, mające istotny wpływ na rozwój sektora kwiaciarskiego. Analizowano kierunek i dynamikę zmian w latach 2005-2015, saldo obrotów i strukturę asortymentową w ujęciu wartościowym i ilościowym. Badania wykazały stały wzrost obrotów, nieznacznie szybszy eksportu niż importu, ale przy wyższym absolutnym poziomie importu i ujemnym saldzie obrotów, pogarszającym się w ujęciu wartościowym, jak również wyższych cenach importowych. Polska jest rosnącym importerem netto kwiatów ciętych żywych, roślin doniczkowych i cebul kwiatowych, a staje się także, w wyniku spadku cen, importerem netto roślin szkółkarskich, będących podstawą polskiego eksportu. Polscy szkółkarze powinni przestawiać się na asortyment roślin o wyższej wartości i poprawiać ich jakość w celu podniesienia cen zbytu.
\end{abstract}

Słowa kluczowe: import, eksport, kwiaty, rośliny doniczkowe, rośliny szkółkarskie

\begin{abstract}
The aim of the study was Polish export and import in ornamental plants, which are the motor of floriculture development. The direction and dynamics of changes in 2005-2015, trade balance and the structure of assortment in terms of value and quantity were studied. Studies show a steady increase in turnover, slightly faster in exports, but with a higher absolute level of imports and a negative turnover balance, deteriorating in value terms, as well as higher import prices. Poland is a growing net importer mainly of cut flowers, pot plants and flower bulbs. However, Poland also has become, as a result of decreasing prices, a net importer of nursery plants, which is the basis of Polish exports. Polish nurserymen should switch to an assortment of plants with a higher value and improve their quality in order to raise selling prices.
\end{abstract}

Key words: import, export, flowers, pot plants, nursery plants

JEL Classification: F14

\section{Wstęp}

Współczesny handel zagraniczny funkcjonuje w warunkach globalizacji i liberalizacji (Kołodko, 2007; za: Grottel, 2016). Oznacza to coraz szersze otwieranie się rynków prowadzące z jednej strony do wzrostu importu, z drugiej dające możliwości rozwoju eksportu. Zapewniając istnienie konkurencji, zjawiska te są motorem rozwoju gospodarki (Grottel, 2016). Wymuszają na producentach działania obniżające koszty produkcji i podnoszące jakość produktów, motywują do specjalizacji i rozwoju dziedzin bardziej opłacalnych, do zwiększania skali produkcji i racjonalnego wykorzystania czynników produkcji (Bożyk, 2004; Piekutowska, 2014). Przykładem może być tu holenderski sektor kwiaciarski (Jabłońska, 2014). W Polsce warunki do widocznego wzrost eksportu

\footnotetext{
${ }^{1}$ dr inż., Samodzielna Pracownia Organizacji i Ekonomiki Ogrodnictwa SGGW, ul. Nowoursynowska 159, 02-766 Warszawa, e-mail: dawid olewnicki@sggw.pl; https://orcid.org/0000-0002-3096-3882

2 prof. dr hab., Samodzielna Pracownia Organizacji i Ekonomiki Ogrodnictwa SGGW, ul. Nowoursynowska 159, 02-766 Warszawa, e-mail: Lilianna_Jablonska@sggw.pl; https://orcid.org/0000-0001-6757-7734
} 
i wewnątrzunijnego importu, w tym rolno-spożywczego, stworzyło przystąpienie do UE (Ślusarczyk, 2009; Nocewska-Twardowska, 2014), choć na rynku kwiaciarskim wzrost obrotów miał miejsce już od połowy lat 90. (Jabłońska, Olewnicki, Kowalczyk, 2012). W 2005 r. wartość eksportu była 3-krotnie, a importu prawie 6-krotnie wyższa niż w 1996r. (Jabłońska, 2007). Szybszy wzrost importu niż eksportu kwiaciarskiego cechuje obroty całej UE, z tym, że o ile wartość importu UE w latach 1995-2010 wzrosła 1,8 razy, a eksportu 2,1 razy przy podobnym absolutnym poziomie (wskaźnik GL 0,942) (Jabłońska i in., 2013; Wieliczko, 2014), to w Polsce był to wzrost odpowiednio 8,8 razy i 3,7 razy przy pogarszającym się ujemnym saldzie obrotów (Jabłońska, Olewnicki, Kowalczyk, 2012). Poprawa salda miała miejsce w 2011 i 2012r., ale w dalszym ciagu było ono na poziomie ok. -115 mln euro (Jabłońska i in., 2015). Dodatnie saldo uzyskiwał handel roślinami szkółkarskimi, które umacniały swoją pozycję w polskim eksporcie, co jest korzystne z punktu widzenia rozwoju polskiego szkółkarstwa. Niekorzystnym był natomiast niski poziom cen uzyskiwanych w ich sprzedaży. Mając na względzie przyszłość sektora kwiaciarskiego w Polsce, w tym istotnego w nim szkółkarstwa ozdobnego, oraz ogromne znaczenie handlu zagranicznego dla rozwoju sektorów, ważne jest systematyczne jego badanie w odniesieniu do krótkich i długich okresów. Celem pracy była analiza zmian w eksporcie i imporcie produktów kwiaciarskich w Polsce w latach 2005-2015.

\section{Metodyka badań}

Przedmiotem badań są zmiany w polskim handlu zagranicznym roślinami ozdobnymi w latach 2005-2015. Badano poziom eksportu i importu, saldo obrotów oraz kierunek i dynamikę zmian w odniesieniu do całej grupy towarowej oraz głównych podgrup produktów kwiaciarskich, wyodrębnionych kodami nomenklatury scalonej CN. Są to kwiaty cięte żywe oraz suszone, rośliny doniczkowe łącznie (tzn. ozdobne z kwiatów, liści i sadzonki), zieleń cięta łącznie (żywa i suszona), cebule kwiatowe oraz rośliny szkółkarskie łącznie (tzn. różaneczniki i azalie, róże, sadzonki, drzewa i krzewy, byliny). Zbadano także znaczenie tychże grup w całym eksporcie i imporcie. Wszystkie zjawiska analizowano w ujęciu wartościowym (euro) i ilościowym (tony). Dynamikę zmian w 11-letnim okresie określono współczynnikiem b prostoliniowej linii tendencji (wartości absolutne) oraz procentową średnioroczną zmianą wyznaczoną funkcją wykładniczą (wartości względne). Poziom obrotów, salda i strukturę asortymentową przedstawiono dla okresów 3-letnich. W analizach wykorzystano niepublikowane dane GUS i CAAC.

\section{Wyniki badań \\ Poziom, tendencje i struktura importu}

Import produktów kwiaciarskich w latach 2005-15 wykazywał generalnie tendencje rosnącą. Łącznie dla całej grupy coroczny wzrost wyniósł 7,6\% w ujęciu wartościowym i 7,2\% ilościowym (tab.1). Malał jedynie import zieleni ciętej - wolumenu o -5,3\%, a wartości o $-8,3 \%$ średniorocznie. Najwyższą dynamikę wzrostu notowano w przypadku kwiatów ciętych suszonych. Co roku importowano ich o $24,1 \%$ więcej za kwotę większą corocznie o 32,5\%, przy wysokim w obu przypadkach współczynniku zmienności. W latach 2005-2007 ich import wynosił średnio 253 tony i 916 tys. euro, a 2013-2015 
1,8 $\mathrm{mln}$ ton i 12,1 mln euro. Relatywnie szybko rósł w badanym okresie import roślin szkółkarskich - średniorocznie o 13,0\% w ujęciu ilościowym i 14,7\% wartościowym. W wartościach absolutnych był to wzrost o 2,51 tys. ton (z 7,9 tys. do 34,0 tys.) i 4,29 mln euro (z 11,8 $\mathrm{mln}$ do 52,2 mln euro) rocznie. O podobną wartość, bo o 4,81 mln euro, rósł co roku import roślin doniczkowych, ale jego wolumen zwiększał się wolniej - o 1,21 tys. ton. Średnioroczny wzrost wynosił odpowiednio $10,7 \%$ i $8,9 \%$. Wyraźnie wolniej wzrastał import kwiatów ciętych żywych - średniorocznie o $4,2 \%$ rósł jego wolumen i o $4,9 \%$ wartość, co odpowiada wzrostowi o 0,51 tys. ton i $2,87 \mathrm{mln}$ euro. Jeszcze niższa dynamika wzrostu notowana była $\mathrm{w}$ imporcie cebul kwiatowych, który wykazywał także najmniejsze wahania. Należy podkreślić, iż w przypadku wszystkich przedstawionych wyżej grup roślin ozdobnych, dynamika wzrostu wartości importu była wyższa niż wolumenu, co wskazuje na płacenie coraz wyższych cen za sprowadzane produkty.

Tabela 1. Poziom, dynamika zmian i struktura importu roślin ozdobnych do Polski w latach 2005-2015

Table 1. The level, dynamics of changes and structure of ornamental plant imports to Poland in 2005-2015

\begin{tabular}{|c|c|c|c|c|c|c|c|c|}
\hline \multirow{3}{*}{ Wyszczególnienie } & \multicolumn{2}{|c|}{ Poziom importu } & \multicolumn{3}{|c|}{ Średnia roczna zmiana } & \multirow{3}{*}{$\begin{array}{c}\text { Współ. } \\
\text { zmienn. } \\
\%\end{array}$} & \multicolumn{2}{|c|}{ Struktura importu } \\
\hline & 2005-07 & $013-15$ & & \multirow{2}{*}{$\%$} & \multirow{2}{*}{$\mathrm{R}^{2}$} & & $2005-07$ & $2013-15$ \\
\hline & \multicolumn{3}{|c|}{ mln euro } & & & & \multicolumn{2}{|c|}{$\%$} \\
\hline Kwiaty cięte żywe & 47,5 & 73,5 & 2,9 & 4,9 & 0,58 & 18,6 & 37,2 & 30,3 \\
\hline Kwiaty cięte suszone & 0,9 & 12,1 & 1,4 & 32,5 & 0,97 & 82,3 & 0,7 & 5,0 \\
\hline Zieleń cięta & 15,8 & 9,7 & $-0,9$ & $-8,3$ & 0,25 & 47,7 & 12,3 & 4,0 \\
\hline Rośliny doniczkowe & 28,2 & 68,8 & 4,8 & 10,7 & 0,82 & 30,9 & 22,1 & 28,4 \\
\hline Cebule kwiatowe & 19,5 & 26,5 & 0,9 & 3,9 & 0,67 & 13,9 & 15,2 & 10,9 \\
\hline Rośliny szkółkarskie & 15,8 & 52,1 & 4,3 & 14,7 & 0,94 & 43,5 & 12,4 & 21,5 \\
\hline Ogólem & 127,7 & 242,7 & 13,2 & 7,6 & $\mathbf{0 , 8 0}$ & 23,9 & 100,0 & 100,0 \\
\hline & & ton & & & & & & \\
\hline Kwiaty cięte żywe & 10,2 & 15,3 & 0,5 & 4,2 & 0,30 & 20,6 & 21,9 & 18,1 \\
\hline Kwiaty cięte suszone & 0,3 & 1,8 & 0,2 & 24,1 & 0,91 & 63,4 & 0,6 & 2,1 \\
\hline Zieleń cięta & 6,9 & 5,2 & $-0,3$ & $-5,3$ & 0,14 & 37,6 & 14,9 & 6,1 \\
\hline Rośliny doniczkowe & 9,6 & 20,2 & 1,2 & 8,9 & 0,62 & 28,2 & 20,8 & 23,9 \\
\hline Cebule kwiatowe & 6,9 & 8,1 & 0,1 & 1,9 & 0,24 & 11,6 & 14,9 & 9,6 \\
\hline Rośliny szkółkarskie & 12,5 & 34,0 & 2,5 & 13,0 & 0,80 & 41,3 & 27,0 & 40,2 \\
\hline Ogólem & 46,4 & 84,6 & 4,3 & 7,2 & 0,719 & 23,4 & 100,0 & 100,0 \\
\hline
\end{tabular}

Źródło: opracowanie własne na podstawie danych GUS i CAAC.

W wyniku przedstawionych zmian wyraźnie zwiększyła się w polskim imporcie rola ozdobnego materiału szkółkarskiego. W latach 2005-07 stanowiły 27\% ilości i $12,4 \%$ wartości całego importu, zaś w latach 2013-15 już 40,2\% i 21,5\% (tab. 1). W ujęciu ilościowym jest to czołowy produkt importowy. W ujęciu wartościowym najwyższe pozycje zajmują kwiaty cięte żywe i rośliny doniczkowe, przy czym rola tych pierwszych wyraźnie obniżyła się, a drugich wzrosła. Udział kwiatów ciętych żywych w wartości importu kwiaciarskiego obniżył się między dwoma podokresami z $37,2 \%$ do $30,3 \%$ i w ilości z 21,9\% do 18,1\%, natomiast roślin doniczkowych wzrósł odpowiednio z 22,1\% do $28,4 \%$ i z $20,8 \%$ do $23,9 \%$. Wzrost znaczenia odnotowano także w przypadku kwiatów ciętych suszonych, zaś spadek zieleni ciętej oraz cebul kwiatowych. 


\section{Poziom, tendencje i struktura eksportu}

Ogółem eksport produktów kwiaciarskich z Polski również wykazywał tendencję rosnąca, $\mathrm{z}$ dynamiką nieznacznie wyższą niż import - rocznie wolumen eksportu rósł o 7,5\%, a wartość o 8,3\% (tab.2). W ostatnim 3-leciu wyeksportowano 69,2 tys. ton za kwotę $105 \mathrm{mln}$ euro. Wśród badanych grup, zmniejszał się jedynie eksport cebul i w efekcie ich udział w wartości eksportu kwiaciarskiego obniżył się do 5\%, podczas gdy na przełomie wieków wynosił ponad 18\% (Jabłońska 2007). Najwyższa dynamika wzrostu eksportu, podobnie jak importu, oraz najwyższe wahania notowane były w przypadku kwiatów ciętych suszonych. Wolumen eksportu rósł średniorocznie o $12,4 \%(0,26$ tys.t), a wartość o 17,2\% (0,66 mln euro). Był to wzrost wolniejszy niż importu, ale i tu kwiaty uzyskiwały coraz wyższe ceny. Relatywnie wysokie tempo wzrostu, ale także niższe niż w imporcie i przy niższych wahaniach, cechowało eksport roślin szkółkarskich. Rósł on rocznie o $9,9 \% \mathrm{w}$ ujęciu ilościowym i 9,0\% wartościowym, a w wartościach absolutnych o 3,18 tys. ton i 2,86 mln euro. Sprzedawano więc stopniowo coraz tańsze produkty (spadek roczny cen o $-0,8 \%$ ). W ujęciu wartościowym wyższa niż w imporcie dynamika wzrostu miała miejsce w eksporcie roślin doniczkowych i wynosiła 11,1\% rocznie, choć ilość eksportowanego towaru rosła jedynie o 3,1\% rocznie, czyli znacznie wolniej niż ilość importu. Oznacza to wyraźny wzrost cen eksportowych, szybszy niż cen importowych. Podobne zjawisko widoczne jest w eksporcie kwiatów ciętych świeżych, którego wartość rosła o $6,4 \%$ rocznie, a wolumen tylko o $1,8 \%$. Uzyskiwanie wyższych cen w eksporcie jest pochodną zmian struktury asortymentowej i wyższej jakości sprzedawanych roślin, co częściowo wynika z rosnącego zjawiska reeksportu, oraz zmian struktury geograficznej.

Tabela 2. Poziom, dynamika zmian i struktura eksportu grup roślin ozdobnych z Polski w latach 2005-2015

Table 2. The level, dynamics of changes and structure of ornamental plant exports from Poland in 2005-2015

\begin{tabular}{|c|c|c|c|c|c|c|c|c|}
\hline \multirow{3}{*}{ Wyszczególnienie } & \multicolumn{2}{|c|}{ Poziom eksportu } & \multicolumn{3}{|c|}{ Średnia roczna zmiana } & \multirow{3}{*}{$\begin{array}{c}\text { Współ. } \\
\text { zmienn. } \\
\%\end{array}$} & \multicolumn{2}{|c|}{ Struktura eksportu } \\
\hline & 2005-07 & $13-15$ & & \multirow{2}{*}{$\%$} & \multirow{2}{*}{$\mathrm{R}^{2}$} & & $2005-07$ & $2013-15$ \\
\hline & \multicolumn{3}{|c|}{ mln euro } & & & & \multicolumn{2}{|c|}{$\%$} \\
\hline Kwiaty cięte żywe & 4,3 & 8,5 & 0,4 & 6,4 & 0,36 & 32,5 & 8,3 & 8,1 \\
\hline Kwiaty cięte suszone & 3,2 & 9,2 & 0,7 & 17,2 & 0,52 & 46,4 & 6,3 & 8,8 \\
\hline Zieleń cięta & 9,6 & 20,8 & 1,2 & 8,6 & 0,77 & 30,9 & 18,7 & 19,8 \\
\hline Rośliny doniczkowe & 6,5 & 15,4 & 1,2 & 11,1 & 0,92 & 36,4 & 12,6 & 14,7 \\
\hline Cebule kwiatowe & 6,6 & 5,2 & $-0,1$ & $-2,0$ & 0,11 & 19,8 & 12,9 & 5,0 \\
\hline Rośliny szkółkarskie & 21,1 & 45,9 & 2,9 & 9,0 & 0,84 & 30,6 & 41,2 & 43,6 \\
\hline Ogólem & 51,3 & 105,0 & 6,2 & 8,3 & 0,914 & 27,2 & 100,0 & 100,0 \\
\hline \multicolumn{9}{|c|}{ tys. ton } \\
\hline Kwiaty cięte żywe & 1,0 & 1,4 & 0,02 & 1,8 & 0,03 & 31,6 & 2,9 & 2,0 \\
\hline Kwiaty cięte suszone & 1,6 & 4,1 & 0,3 & 12,4 & 0,46 & 45,8 & 4,5 & 6,0 \\
\hline Zieleń cięta & 6,5 & 9,8 & 0,3 & 4,1 & 0,35 & 22,0 & 18,1 & 14,2 \\
\hline Rośliny doniczkowe & 3,1 & 4,0 & 0,1 & 3,1 & 0,58 & 12,8 & 8,7 & 5,7 \\
\hline Cebule kwiatowe & 3,1 & 1,7 & $-0,1$ & $-6,2$ & 0,40 & 30,9 & 8,7 & 2,5 \\
\hline Rośliny szkółkarskie & 20,4 & 48,2 & 3,2 & 9,9 & 0,65 & 35,4 & 57,1 & 69,6 \\
\hline Ogólem & 35,7 & 69,2 & 4,2 & 7,5 & 0,729 & 26,6 & 100,0 & 100,0 \\
\hline
\end{tabular}

Źródło: opracowanie własne na podstawie niepublikowanych danych GUS i CAAC. 
W strukturze eksportu kwiaciarskiego wzmocniła się czołowa rola ozdobnego materiału szkółkarskiego z udziałem w wolumenie i wartości wynoszącym 69,6\% i 43,6\% w latach 2013-15 (tab.2). Na drugim miejscu znajduje się zieleń cięta, a na trzecim rośliny doniczkowe. W obu przypadkach nieznacznie wzrósł udział w wartości eksportu do 19,8\% i 14,7\%, zaś zmniejszył w jego wolumenie do 14,2\% i 5,7\%. Niski jest natomiast w eksporcie udział kwiatów ciętych żywych i suszonych oraz wspomnianych wyżej cebul kwiatowych. Z analizy porównawczej struktury eksportu w ujęciu ilościowym i wartościowym wynika, że do produktów uzyskujących relatywnie wyższe ceny należą kwiaty cięte świeże i pokojowe rośliny doniczkowe.

\section{Saldo obrotów roślinami ozdobnymi}

Rozpatrując obroty łączne całej grupy, wyraźnie wyższy jest absolutny poziom importu niż eksportu, co skutkuje ujemnym saldem obrotów, sukcesywnie malejącym w ujęciu wartościowym. W latach 2005-2006, czyli po włączeniu Polski w struktury UE, wartość importu była 2,3 razy wyższa niż eksportu przy saldzie wynoszącym -63,4 mln euro, a w latach 2013-2015 także 2,3 razy, ale przy saldzie $-137,8 \mathrm{mln}$ euro (tab. 3). W ujęciu ilościowym ujemne saldo waha się na poziomie kilkunastu tysięcy ton, bez wyraźnej tendencji zmian. Różnica poziomu eksportu i importu wynosi jedynie około $22 \%$ na korzyść importu, co wskazuje, że do Polski importuje się rośliny droższe, zaś eksportuje tańsze.

Tabela 3. Saldo obrotów handlu zagranicznego roślinami ozdobnymi w Polsce w latach 2005-2015

Table 3. Balance of foreign trade in ornamental plants in 2005-2012

\begin{tabular}{|c|c|c|c|c|c|c|c|c|}
\hline Wyszczególnienie & $\begin{array}{l}2005- \\
2006\end{array}$ & $\begin{array}{l}2007- \\
2009\end{array}$ & $\begin{array}{l}2010- \\
2012\end{array}$ & $\begin{array}{l}2013- \\
2015\end{array}$ & $\begin{array}{l}2005- \\
2006\end{array}$ & $\begin{array}{l}2007- \\
2009\end{array}$ & $\begin{array}{l}2010- \\
2012\end{array}$ & $\begin{array}{l}2013- \\
2015\end{array}$ \\
\hline & \multicolumn{4}{|c|}{ mln euro } & \multicolumn{4}{|c|}{ tys. ton } \\
\hline Kwiaty cięte żywe & $-38,5$ & $-57,3$ & $-60,7$ & $-65,0$ & $-8,3$ & $-13,9$ & $-15,0$ & $-14,0$ \\
\hline Kwiaty cięte suszone & 0,4 & 5,4 & $-2,3$ & $-2,9$ & 0,9 & 2,5 & 0,7 & 2,3 \\
\hline Zieleń cięta & $-3,7$ & $-5,5$ & 9,2 & 11,1 & 0,8 & 0,8 & 2,4 & 4,7 \\
\hline Rośliny doniczkowe & $-18,6$ & $-39,9$ & $-47,1$ & $-53,4$ & $-5,3$ & $-13,2$ & $-16,5$ & $-16,3$ \\
\hline Cebule kwiatowe & $-10,7$ & $-18,5$ & $-20,2$ & $-21,3$ & $-2,9$ & $-6,0$ & $-6,4$ & $-6,4$ \\
\hline Rośliny szkółkarskie & 7,6 & 3,1 & $-0,8$ & $-6,3$ & 9, & 11,9 & 22,1 & 14,2 \\
\hline Ogółem & $-63,4$ & $-114,1$ & $-128,1$ & $-137,8$ & $-5,5$ & $-19,6$ & $-12,7$ & $-15,48$ \\
\hline
\end{tabular}

Źródło: opracowanie własne na podstawie niepublikowanych danych GUS i CAAC

O ujemnym saldzie handlu zagranicznego produktami kwiaciarskimi decydują głównie obroty żywymi kwiatami ciętymi i roślinami doniczkowymi. Saldo obrotów pierwszymi wzrosło $\mathrm{w}$ badanym okresie $\mathrm{z}-38,5 \mathrm{mln}$ do $-65,0 \mathrm{mln}$ euro, drugimi $\mathrm{z}-18,6 \mathrm{mln}$ do $-53,4 \mathrm{mln}$ euro. Pogarszało się również ujemne saldo obrotów w ujęciu ilościowym. Polska staje się coraz większym importerem netto tych dwóch grup roślin. Wysokie ujemne saldo notuje się także w obrotach cebulami kwiatowymi, które obniżyło się z $-10,7$ mln do $-21,3$ mln euro. Ale i w handlu suszonymi kwiatami ciętymi i roślinami szkółkarskimi następowało stopniowe pogarszanie się salda. W przypadku roślin szkółkarskich obniżyło się z 7,6 mln do -6,3 mln euro, zaś kwiatów suszonych z 0,4 mln do 
$-2,9$ mln euro, przy wahaniach dodatniego salda w ujęciu ilościowym. Poprawa salda miała miejsce jedynie w obrotach zielenią ciętą z $-3,7 \mathrm{mln}$ do $11,1 \mathrm{mln}$ Euro oraz z 0,8 tys. do 4,7 tys. ton. Tak więc w ostatnich latach tylko w przypadku zieleni ciętej i kwiatów suszonych Polska jest eksporterem netto.

\section{Podsumowanie}

W latach 2005-2015 obroty handlu zagranicznego produktami kwiaciarskimi w Polsce wykazywały tendencję rosnąca, przy nieznacznie wyższej dynamice wzrostu eksportu, co jest zjawiskiem pozytywnym. Wzrost notowano we wszystkich grupach roślin, z wyjątkiem importu zieleni ciętej i eksportu cebul kwiatowych. Niekorzystnym jest natomiast wyraźnie wyższy absolutny poziom importu niż eksportu, co skutkuje ujemnym saldem obrotów, sukcesywnie pogarszającym się w ujęciu wartościowym. Wartość importu była ponad 2,3-krotnie wyższa niż importu przy saldzie wynoszącym -63,42 mln euro w latach 2005-2006 i -137,75 mln euro w latach 2013-2015. W ujęciu ilościowym różnica poziomu eksportu i importu wynosiła jedynie około $22 \%$ na korzyść importu, co wskazuje, że do Polski importuje się rośliny droższe, zaś eksportuje tańsze. Pozytywnym jest zmniejszanie się różnicy cen w wyniku nieco szybszego wzrostu cen w eksporcie niż imporcie, ale proces ten zachodzi bardzo wolno. Te pierwsze rosły średniorocznie o $0,8 \%$, te drugie o 0,48\%, a różnica zmniejszyła się z 1,93-krotności do 1,85-krotności. Nie napawa optymizmem sytuacja w handlu roślinami szkółkarskimi. Choć w dalszym ciągu umacnia się ich czołowa pozycja $\mathrm{w}$ polskim eksporcie (udział 70\% w ilości, 44\% w wartości), to wzrostowi eksportu towarzyszy szybszy wzrost importu przy spadku cen w tym pierwszym i wzroście w drugim. W efekcie, od początku obecnej dekady notowane jest ujemne saldo wartości obrotów, stopniowo pogarszające się. Polska jest więc nie tylko rosnącym importerem netto kwiatów ciętych, roślin doniczkowych czy cebul kwiatowych, ale powoli staje się importerem netto roślin szkółkarskich, co stawia znak zapytania przy dalszym rozwoju sektora szkółkarskiego. Producenci szkółkarskich roślin ozdobnych powinni podejmować działania zmierzające do zmian w strukturze produkcji na korzyść asortymentu o wyższej wartości oraz poprawiać ich jakość, by uzyskiwać wyższe ceny.

\section{Literatura}

Bożyk, P. (2004). Zagraniczna i międzynarodowa polityka ekonomiczna (Foreign and International Economic Policy), PWE, Warszawa.

Grottel, M. (2016). Protekcjonizm we współczesnym handlu międzynarodowym (Protectionism in Contemporary International Trade). International Business and Global Economy, 35(1), 69-80.

Jabłońska, L. (2007). Ekonomiczne aspekty rozwoju sektora kwiaciarskiego w Polsce (Economic Aspects of the Development of the Floriculture Sector in Poland). Wydawnictwo SGGW.

Jabłońska, L. (2014). Holenderski sektor kwiaciarski w pierwszej dekadzie XXI w. (Dutch Floriculture in the First Decade of XXI Century). Zeszyty Naukowe SGGW Problemy Rolnictwa Światowego, 14(1), 34-43.

Jabłońska, L., Bońkowska, A., Olewnicki, D., Stefanowska, A. (2013). Handel zagraniczny Unii Europejskiej roślinami ozdobnymi (European Union's Foreign Trade of Ornamental Plants). Zeszyty Naukowe SGGW Problemy Rolnictwa Światowego, 13(1), 37-48.

Jabłońska, L., Olewnicki, D., Kowalczyk, A. (2012). Polski handel zagraniczny roślinami ozdobnymi w latach 1996-2009 (Polish Foreign Trade in Ornamental Plants in 1996-2009). Zeszyty Naukowe SGGW Problemy Rolnictwa Światowego, 12(2), 25-35. 
Jabłońska, L., Olewnicki, D., Kowalczyk, D. (2015). Zmiany w polskim handlu zagranicznym roślinami ozdobnymi w latach 2005-2012 (Changes in Polish Foreign Trade of Ornamental Plants Over the Years 2005-2012). Zeszyty Naukowe SGGW Problemy Rolnictwa Światowego, 15(2), 65-74.

Nacewska-Twardowska, A. (2014). Zmiany w wymianie handlowej Polski produktami rolnospożywczymi z krajami pozaunijnymi (Changes in Polish Trade of Agri-food Products with Non-EU Countries). Zeszyty Naukowe SGGW Problemy Rolnictwa Światowego, 14(2), 139-148.

Piekutowska, A. (2014). Handel zagraniczny jako źródło zwiększenia efektywności gospodarowania (Foreign Trade as a Source of Improving Performance). Studia Ekonomiczne. Zeszyty Naukowe Uniwersytetu Ekonomicznego w Katowicach, 180(2), 227-235.

Ślusarczyk, B. (2009). Konkurencyjność polskich wyrobów rolnospożywczych na rynkach krajów UE, a zwłaszcza na rynku niemieckim (Competitiveness of Polish Agri-Food Product in the EU with Special Focus on the German Market). Roczniki Naukowe SERiA, 11(3), 361-365.

Wieliczko, B. (2014). Konkurencyjność sektora rolno-spożywczego UE w świetle wyników handlu zagranicznego wybranych państw (Competitiveness of the EU Agri-Food Sector in the Light of Foreign Trade Balance of Chosen Countries). Zeszyty Naukowe SGGW Problemy Rolnictwa Światowego, 14(2), 99-104.

\section{Do cytowania / For citation:}

Olewnicki D., Jabłońska L. (2018). Polski handel zagraniczny produktami kwiaciarskimi. Problemy Rolnictwa Światowego, 18(1), 176-182; DOI: 10.22630/PRS.2018.18.1.16

Olewnicki D., Jabłońska L. (2018). Polish Foreign Trade in Floricultural Product (in Polish). Problems of World Agriculture, 18(1), 176-182; DOI: 10.22630/PRS.2018.18.1.16 